\title{
Stapled Heamorrhoidopexy Complications - A Clinical Study
}

Dr. Narayan Hebsur ${ }^{1}$, Dr. Arun Walwekar ${ }^{2}$, Dr. Abhilash ${ }^{3}$

\footnotetext{
${ }^{1}$ Consulting Surgeon, Hebsur Hospital, Hubli Karnataka, India

${ }^{2}$ Senior Resident, Department of General Surgery, Kims, Hubli Karnataka, India

${ }^{3}$ Post Graduate Department of General Surgery, Kims, Hubli Karnataka, India
}

*Corresponding author: Dr. Arun Walwekar

Stapled haemorrhoidpexy is one of the surgery for treatment of haemorrhoids, Here a circumferential strip of mucosa is removed about $4 \mathrm{~cm}$ above dentate line, The complications of this procedure include severe pain, bleeding, thrombosis, fissure, perianal intramural heamatoma, anal stenosis and faecal or flatal incontinence. In this study a review of total of 94 patients treated by stapled heamorrhoidopexy has been done for complications and it's found to be $16.92 \%$, clinically patients are evaluated at 6 weeks, 3 months and 1 year after surgery. Most common complication was found to be bleeding $11.28 \%$ mainly because of improper application of purstring sutures and staplers; anal stricture $1.8 \%$ was treated with dilatation, anal fissures $1.8 \%$ was treated conservatively.

Keywords: Stapled haemorrhoidopexy, complications, circular stapler, bleeding, and purse-string sutures.

Copyright @ 2020: This is an open-access article distributed under the terms of the Creative Commons Attribution license which permits unrestricted use, distribution, and reproduction in any medium for non-commercial use (NonCommercial, or CC-BY-NC) provided the original author and source are credited.

\section{INTRODUCTION}

Cushions of vascular tissue in the anal region undergo pathological changes an develop internal haemorrhoids. The cushions in anal region along with internal anal sphincter have important role of maintaining continence, to allow the complete closure of the anal canal [3].

Hemorrhoids are normal, vascular tissue within the submucosa located in the anal canal; these can occur causing symptoms such as itching, bleeding, mucosal or fecal soiling and pain. Hemorrhoids are graded according in their severity and tendency to prolapse. Sclerotherapy and/or rubber band ligation can be used in conservative management of grade 1 and 2 hemorrhoids, Grade 3 and 4 hemorrhoids that prolapsed require surgical treatment.

Circular stapled rectal hemorrhoidopexy, sometimes known as circular stapled rectal mucosectomy, is one of the surgeries for haemorrhoids. The operation reducing the available rectal mucosa for the prolapsed by reducing size of vascular cushions and reducing by interrupting their blood supply to cushions.With circular stapler,circumferential strip of rectal mucosa of approximately 4 centimeter above dentate line was removed.probably interrupting hemorrhoidal vessels and stretching prolapsed mucosa.

\section{PATIENTS AND METHODS}

A total of 94 patients were operated over 18 months period between 2014 to 2017, main inclusion criteria was symptomatic haemorrhoidal disease, Exclusion criteria were acute hemorrhoidal episodes with thrombosis, prior hemorrhoidectomy, and intercurrent anal pathology (ie, fistula and/or fissure. Based on patients preference and anaesthesiologist's opinion.Based on patient's preference and anaesthesiologist's opinion the operation was done either under general anaesthesia or spinal anaesthesia, preferebaly spinal anesthesia by the same operating surgeon. A cleaning enema was given preoperatively. Patients were placed in a position for lithotomy.

A circular anal dilatator was introduced to reduce the prolapse of the anoderm and parts of the anal mucous membrane. After removal of the obturator, the prolapsed mucous membrane falls into the lumen of the circular anal dilatator. With nonabsorbable surgical 2-0 polypropylene suture, purse string suturing placed circumferentially through the window of anoscope 3-5 cms above the dentate line, followed by a haemorrhoidal circularstapler was placed in anal canal positioned and fired. 
All patients received a normal diet postoperatively and were given lactulose for preventing hard stool. Patients are called up for follow up and examination done at 6 and 12 weeks postoperatively. Postoperative complications (with special regard to rectal stenosis), frequency, defecation habit and return to work postoperatively were evaluated. In special regard to hemorrhoid recurrence additional follow up examination was done after 1 year and a proctologic examination was performed and patients were evaluated about defication habits.

\section{RESULTS}

A total of 104 patients were included with mean age being 44years. The commonest problem before operation reported being frequent bleeding. Other problems were complaining of a mass at the anus, itching, soiling, discharge and pain. Most common indication for surgery was prolapsed internal haemorrhoids most of which was of grade 3 .

\section{Per op complications}

In 4 patients stapler could not be fixed completely and only tissue cutting was done, stapler was not fixed causing continuous bleeding, such patients were treated with continuous interlocking sutures using 3-0 vicryl and later healed completely without any complications.

In 6 cases due to faulty suturing technique used for purse string sutures, staplers not fixed at 10 and 11 'o clock position and these bleeding points sutured using 3-0 vicryl, bleeding stopped and later no further complications seen.

\section{Postoperative Follow Up within the First 6 Weeks-}

In early postoperative period almost all patients had pain with mean VAS score of 3 , more during defeacation. Six patients had developed anal fissures $2^{\text {nd }}$ day onwards which lasted for 15 days and were treated conservatively. Two patients developed post haemorrhoidopexy stricture and were treated with anal daltation at regular intervals. $8 \%$ of patients had flatus incontinence for 15-20 days and later they recovered without any treatment

\section{At one year follow up}

At one year follow up almost all patients were relived of symptoms except for 2 patients of anal stenosis and 8 patients with minimal pain during defeacation, no patients were found to have anal incontinence.

\section{DISCUSSION}

Stapled heamorhoidopexy is one among the newer approach for treatment of haemorrhoids which was found to have less pain compared to other conventional procedures being done for the same, in this study an emphasis was made to evaluate other complications of this procedure apart from pain. Some articles demonstrate low complication rate of stapled haemorrhoidopexy then other methods.

Overall stapled haemorrhoidopexy complications are said to be similar as conventional excisional haemorrhoidectomy. Postoperatively, most common complication reported was bleeding; there are studies which show post op bleeding rates compared with other haemorrhoidectomy methods are lower. With atapled haemorrhoidopexy bleeding said to occur immediately after surgery. The suggested cause for bleeding is often due to arteolar bleed along staple line due to defective technique which results to mucosal injury and can also be due to inflammation or rejection of the staples[10,12], in this study total of 6 patients had bleeding due to improper fixation of circular staplers.

In our study no patients presented with thrombosed external haemorrhoids, however there were many trails showing thrombosed external haemorrhoids is one of complication of stapled haemorrhoidectomy $[5,6]$.It was suggested that the staple line distance from the anal verge may lead to the development of thrombosed external haemorrhoids development along with the significance of external disease, Management options for post-operative external haemorrhoids included conservative management (sitz baths) and surgical excision[5], Other articles have also suggested the avoidance of constipation via the regular use of lactulose[6].

Unique risk associated with stapled hemorrhoidopexy is defective stapling [2] that has been shown most often to occur secondary to problems with materials or technical errors. Complications including anastomotic dehiscence have been reported secondary to the use of a defective stapler, along with incomplete stapling in few studies [2, 6, 7], In our study in 6 patients staplers were failed to apply at 10 and $11^{\prime} 0$ clock positon due to faulty technique.

Pruritis ani, anal fissures, and skin tags were commonly reported, as was mucosal prolapse. It is proposed that secondary to the inclusion of excessive mucosal folds in the staple line anal fissures may occur. As a result, the development of a fissure that will often not heal unless the staples are removed due to mucosal fold breakdown [15].

Late complication unique to stapled hemorrhoidopexy was proctitis[15] and was thought to be secondary to ischemia as shown in few studies, However in our study none of patients developed proctitis and 6 patients had developed anal fissure. In our study 2 patients developed anal strictures. Risk factors for the development of strictures include, residual sphincter hypertonia, include higher-grade hemorrhoidal disease and the presence of muscle fibers in resected tissue. With digital dilatation in clinic most cases are successfully managed. 
However, for unsuccessful dialatation, commonly reported secondary intervention is anoplasty.Few authors reported medical management with fiber supplementation and laxatives. Following the procedure Recurrence of hemorrhoids has been recorded in many studies. $8 \%$ of patients had flatus incontinence, It was proposed that the incontinence may be secondary to the stretching of the anal canal during insertion or firing of the stapler or use of anal dilator devices and that their use can lead to fragmentation of internal sphincter, if excessive or prolonged[14].

The judicious careful use of an Eisenhammer retractor for purse string suture insertion has shown to reduce the incidence of these complications [12]. Tenesmus was more commonly reported in stapled hemorrhoidopexy in many studies and authors have attributed this to the presence of a low rectal suture.

Almost all patients had pain with average( VAS score of 3) in early postop period but there are many studies showing lower incidence rate of postoperative pain in stapled hemorrhoidopexy than other methods of hemorrhoidectomy.

In addition, the procedure was also identified to be associated with a shorter duration and reduced severity of pain. Although the etiology remains unclear, postulated causes included the incorporation of smooth muscle into the doughnut and the induction of a staple line inflammatory response in the rectal ampulla resulting in irritability and pain.

Placement of the purse-string suture in relation to the dentate line, whether this be too far above or below the line, or with an inadequate depth has also been suggested [18]. These factors are thought to contribute to the development of prolonged pain and that ideal placement of the suture approximately 3 to 4 $\mathrm{cm}$ above the dentate line may result in less pain being experienced.

The presence of persistent hemorrhoidal disease, sphincter spasm, rectal spasm, high anal resting pressures, anal fissures, retained staples, and fibrosis around the staple line, wound dehiscence, and sepsis, were also identified as contributing factors to excessive and/or prolonged pain $[18,5]$.

\section{CONCLUSION}

In many studies Stapled hemorrhoidopexy has been found to cause less post-operative pain [17] and is not assocated with greater morbitidity than other conventional techniques, however in our study apart from pain, emphasis was made on other complications of this procedure including bleeding, stricture, faecal incontinence and others, There are other studies showing lesser and almost equal incidence of these complications. We conclude that stapled haemorrhoidopexy is safe procedure for treatment of grade 3 and 4 heamorrhoids, however the treating surgeon should always look for other complications of this procedure in post op period and treat accordingly.

\section{REFRENCES}

1. Porrett LJ, Porrett JK, Ho YH. Documented complications of staple hemorrhoidopexy: A systematic review. International surgery. 2015 Jan;100(1):44-57.

2. Lai HJ, Jao SW, Su CC, Lee MC, Kang JC. Stapled hemorrhoidectomy versus conventional hemorrhoidectomy for acute haemorrhoidal crisis. J Gastrointest Surg. 2007;11(12):1654-1661.

3. Sutherland LM, Burchard AK, Matsuda K, Sweeney JL, Bokey EL, Childs PA, Roberts AK, Waxman BP, Maddern GJ. A systematic review of stapled hemorrhoidectomy. Archives of Surgery. 2002 Dec 1;137(12):1395-406.

4. Ortiz H, Marzo J, Armendáriz P, De Miguel M. Stapled hemorrhoidopexy vs. diathermy excision for fourth-degree hemorrhoids: a randomized, clinical trial and review of the literature. Dis Colon Rectum. 2005;48(4):809-815.

5. Oughriss M, Yver R, Faucheron JL. Complications of stapled hemorrhoidectomy: a French multicentre study. Gastroenterol Clin Biol. 2005;29(4):429433.

6. Jongen J, Bock JU, Peleikis HG, Eberstein A, Pfister K. Complications and reoperations in stapled anopexy: learning by doing. Int J Colorectal Dis. 2006;21(2):166-171.

7. Sobrado CW, Cotti GC, Coelho FF, Rocha JR. Initial experience with stapled hemorrhoidopexy for treatment of hemorrhoids. Arq Gastroenterol. 2006;43(3):238-242.

8. Nisar PJ, Acheson AG, Neal KR, Scholefield JH. Stapled hemorrhoidopexy compared with conventional haemorrhoidectomy: systematic review of randomized, controlled trials. Dis Colon Rectum. 2004;47(11):1837-1845.

9. Palimento D, Picchio M, Attanasio U, Lombardi A, Bambini C, Renda A. Stapled and open hemorrhoidectomy: randomized controlled trial of early results. World J Surg. 2003;27(2):203-207.

10. Chen JS, You J-F. Current status of surgical treatment for haemorrhoids - systematic review and meta-analysis. Chang Gung Med J. 2010;33(5):488-499.

11. Brusciano L, Ayabaca SM, Pescartori M, Accarpio GM, Cavallari F, Ravo B. Reinterventions after complicated or failed stapled hemorrhoidopexy. Dis Colon Rectum. 2004;47(11):1846-1851.

12. Peng BC, Jayne DG, Ho YH. Randomized trial of rubber band ligation vs stapled hemorrhoidectomy for prolapsed piles. Dis Colon Rectum. 2003;46(3):291-297..

13. Touzin E, Hegge S, McKinley C. Early experience of stapled hemorrhoidectomy in a community hospital setting. Can J Surg. 2006;49(5):316-320. 
14. Stapled hemorrhoidectomy: surgical notes and results. Mascagni D, Zeri KP, Di Matteo FM, Peparini N, Maturo A, Berni A, Hepatogastroenterology. $2003 \quad$ Nov-Dec; 50(54):1878-82.

15. Complications after stapled hemorrhoidectomy: can they be prevented? Ravo B, Amato A, Bianco V, Boccasanta P, Bottini C, Carriero A, Milito G, Dodi G, Mascagni D, Orsini S, Pietroletti R, Ripetti V, Tagariello GBTech Coloproctol. 2002 Sep; 6(2):83-8.

16. Hetzer FH, Demartines N, Handschin AE, Clavien PA. Stapled vs excision hemorrhoidectomy: long- term results of a prospective randomized trial. Archives of Surgery. 2002 Mar 1;137(3):337-40.

17. Gravié JF, Lehur PA, Huten N, Papillon M, Fantoli M, Descottes B, Pessaux P, Arnaud JP. Stapled hemorrhoidopexy versus milligan-morgan hemorrhoidectomy: a prospective, randomized, multicenter trial with 2-year postoperative follow up. Annals of surgery. $2005 \mathrm{Jul} ; 242(1): 29$.

18. Circular stapled hemorrhoidopexy: experience of a single center with 445 cases. Uras C, Baca B, Boler DE; World J Surg. 2008 Aug; 32(8):1783-8. 